\title{
Diabetic Control in Patients Treated with Once or Twice-Daily Insulin Injections, Including a Comparison of Conventional Beef and Highly Purified Pork Insulins
}

\author{
R. S. Gray ${ }^{1}$, D. Q. Borsey ${ }^{1}$, D. M. Fraser ${ }^{1}$, A. B. Kurtz ${ }^{3}$, S. Rainbow ${ }^{4}$, A. F. Smith ${ }^{2}$, L. J. P. Duncan ${ }^{1}$ \\ and B. F. Clarke ${ }^{1}$ \\ ${ }^{1}$ Diabetic and Dietetic Department and ${ }^{2}$ Department of Clinical Chemistry, Royal Infirmary, Edinburgh; ${ }^{3}$ Institute of Nuclear Medicine, \\ Middlesex Hospital Medical School, London and ${ }^{4}$ Department of Medical Biochemistry, University Hospital of Wales, Cardiff, UK
}

Summary. Twenty patients were changed from a single daily injection of beef insulin (a mixture of soluble and protamine zinc insulin) to two daily injections (mixtures of soluble and isophane insulins). This was associated with a reduction, one month later, in the concentration of glycosylated haemoglobin $\left(\mathrm{HbA}_{1}\right)$ and in the degree of late evening glycosuria. A reduction was shown 6 months later in antibody binding of beef and pork insulin by serum. Subsequent conversion to a twice daily regime of highly purified pork insulin was not associated with further improvement in diabetic control, but was associated after 1 month with a reduction in daily insulin dose, and after 5 months with a further reduction in antibody binding of beef and pork insulin by serum. Patients failing to show a $\mathrm{C}$-peptide response to intravenous glucagon had a fall in $\mathrm{HbA}_{1}$ after conversion from a once to a twice daily insulin regime, which correlated inversely with insulin antibody binding estimated at the beginning of the study.

Key words: $\mathrm{HbA}_{1}$, glycosuria, insulin antibody, Cpeptide, conventional beef insulin, highly purified pork insulin

Assay of the total glycosylated haemoglobin $\left(\mathrm{HbA}_{1}\right)$ concentration in blood provides an index of the integrated blood glucose concentration of the previous few weeks [1-3]. We have studied $\mathrm{HbA}_{1}$ concentrations in blood in a group of young Type 1 (insulindependent) diabetics who were treated sequentially as outpatients with once daily conventional beef insulin, then with twice daily conventional beef insulin and finally with twice daily highly purified pork insulin. Our main aim was to establish whether diabetic control can be improved by substitution of a twice daily for a once daily insulin regime or by substitution of highly purified pork for conventional beef insulin.

\section{Patients and Methods}

\section{Patients}

Twenty patients (seven males and 13 females) were studied with a mean age of 27 years (range 16-38 years), a mean duration of diabetes of 8 years (range 2-23 years) and mean weight of $103 \%$ (range $87-120 \%$ ) ideal body weight [4] at the start of the study. Their mean age at diagnosis of diabetes was 19 years (range 7-32 years). Each patient had received a single morning (before breakfast) injection of soluble insulin and protamine zinc insulin, both beef insulins (Wellcome), since diagnosis of diabetes. The mean post-prandial plasma glucose concentration at six consecutive outpatient clinic attendances before this study, was less than $15 \mathrm{mmol} / \mathrm{l}$ in all subjects.

Each patient had a normal full blood count, normal concentrations of serum creatinine, plasma urea and electrolytes, normal liver function tests and plasma proteins. None had proteinuria and only three patients had minimal background diabetic retinopathy.

\section{Study Protocol}

All patients attended the outpatient clinic, 2-3 h after breakfast and morning insulin injection, at monthly intervals for 13 months (14 attendances) during which no attempt was made to alter their dietary or exercise regimens. For the first two months (three attendances) they continued to receive a single daily injection (before breakfast, $0800-0830 \mathrm{~h}$ ) of soluble and protamine zinc insulin and were then all converted to twice daily (before breakfast and before tea, 1730-1800 h) soluble and isophane insulin (Wellcome) - the initial dose of each insulin being recommended by a doctor, subsequent changes being made by the patient as indicated by urine tests for glucose and the occurrence of hypoglycaemia. Throughout the study, patients were told to adjust insulin doses to reduce glycosuria to a minimum without inducing symptomatic hypoglycaemia.

At the ninth clinic attendance, the 20 patients were divided into two groups with a similar duration of diabetes and C-peptide response to IV glucagon (vide infra). There were no significant differences between the two groups in respect of age, insulin anti- 


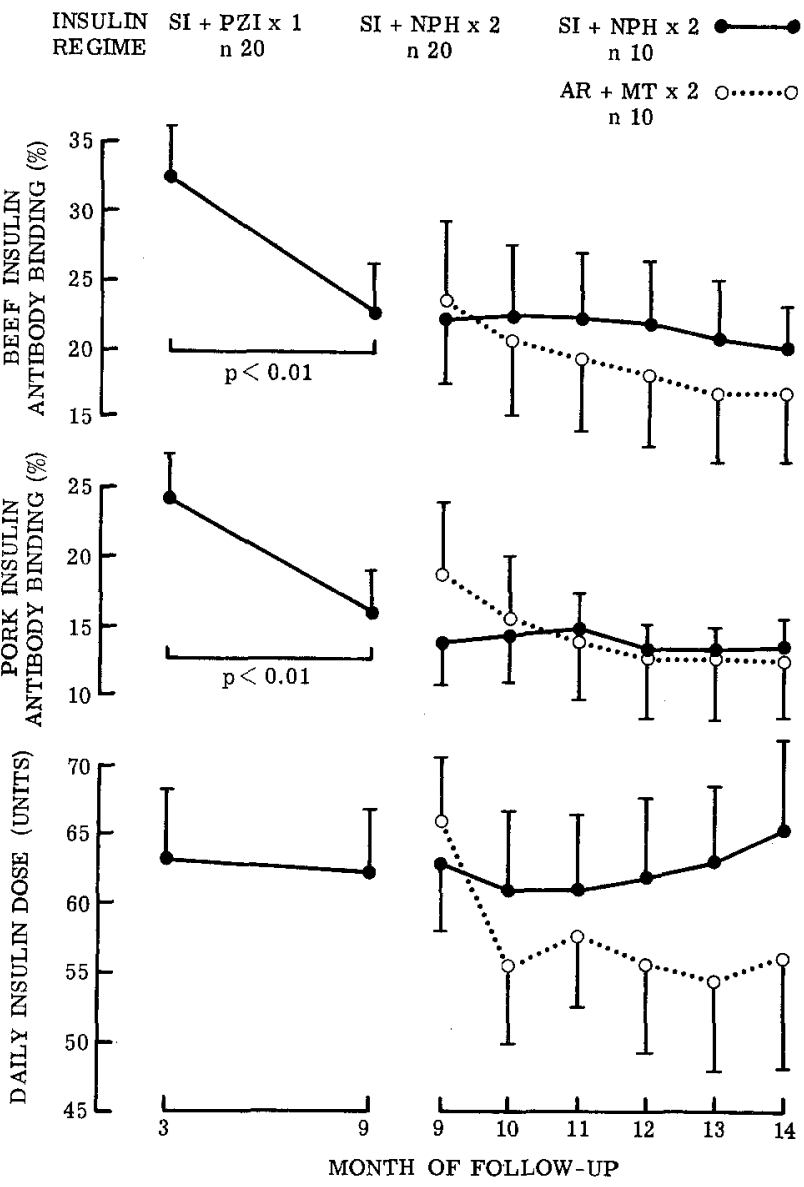

Fig. 1. Change in antibody binding of beef and pork insulin by serum (mean \pm SEM) and in daily insulin dose following conversion from a once daily conventional beef insulin regime to a twice daily conventional beef insulin regime, and then to a twice daily highly purified pork insulin regime. $S I=$ soluble insulin, $P Z I=$ protamine zinc insulin, $N P H=$ isophane insulin, $A R=$ Actrapid insulin, $M T=$ Monotard insulin

body binding, percentage ideal body weight or daily insulin dose. Ten patients were converted to twice daily Actrapid (Novo) insulin and Monotard (Novo) insulin having been advised to reduce their daily dose by approximately $10 \%$ according to the manufacturer's recommendations, while the remaining ten patients continued to take twice daily soluble and isophane insulin.

Throughout the study, each patient recorded symptomatic hypoglycaemic episodes, daily insulin dose and second sample urine tests (Clinitest) carried out four times a day (before breakfast, $0800-0830 \mathrm{~h}$, before lunch, $1200-1230 \mathrm{~h}$, before tea $1730-1800 \mathrm{~h}$ and late evening, $2200-2230 \mathrm{~h}$ ) on two days each week. A scoring system was devised to enable each subject's degree of glycosuria to be expressed as a mean for a given time of day, for a given month: $2 \%=5,1 \%=4,3 / 4 \%=3,1 / 2 \%=2$, $1 / 4 \%=1$ and aglycosuria $=0$.

\section{Estimations}

At each clinic attendance, venous blood was assayed for plasma glucose, $\mathbf{H b A}_{1}$, haemoglobin and reticulocytes. At the third and ninth to fourteenth (inclusive) attendances, venous blood was obtained for estimation of insulin antibody binding. At the third and ninth attendances an IV $1 \mathrm{mg}$ glucagon stimulation test was performed when post-prandial venous blood samples were obtained at $0,2,5$ and $10 \mathrm{~min}$ for plasma glucose and C-peptide estimation.

The binding of ${ }^{125} \mathrm{I}$-labelled insulin by serum samples was determined by a method using polythylene glycol separation [5]. Non-specific binding did not exceed $1.5 \%$ and all samples were analyzed in one assay, with precision of 2.5. (CV) across the range. Results are expressed as percentage of labelled insulin bound (using either labelled beef or labelled pork insulin).

C-peptide was measured by radioimmunoassay using a modification of the method of Heding [6]. Antibody M1230 raised against human C-peptide was used at an initial dilution of $1 / 25,000$. The detection limit of the assay was $0.04 \mathrm{nmol} / 1$ (calculated as 2 SD from 0 ). Cross reaction with human proinsulin was $11 \%$ on a molar basis. The interassay coefficient of variation was $6 \%$. Antibody M 1230, human C-peptide standard and iodinated tyrosylated C-peptide were gifts of the Novo Research Institute, Copenhagen, Denmark. The C-peptide response to the glucagon stimulation test was expressed as the difference between the basal and peak concentration ( $\Delta \mathrm{C}-\mathrm{P}$ ). Plasma glucose exceeded $2.0 \mathrm{mmol} / 1$ throughout the test in each patient.

Plasma glucose was estimated by a standard glucose oxidase method [7].

$\mathrm{HbA}_{1}$ was measured by the column chromatographic technique of Kynoch and Lehmann [8]. Reversible and stable $\mathrm{HbA}_{1}$ were not separated by dialysis of red cells [9]. Between batch precision, estimated by repeat analysis of specimens from patients showed a coefficient of variation of $3.5 \%$. The normal range in non-diabetics in our laboratory is $5.2-8.4 \%$.

Statistical analyses were carried out using the Wilcoxon rank sum test or the Spearman rank correlation test, as appropriate. Results are expressed as mean \pm SEM unless otherwise stated.

\section{Results}

\section{Antibody Binding of Insulin and Daily Insulin Dose}

Beef and pork insulin antibody binding estimated for serum samples from clinic attendance $9(23.0 \pm 3.7$ and $16.2 \pm 3.1 \%)$ were significantly less $(p<0.01)$ than for serum samples from attendance $3(32.4 \pm$ 7.2 and $24.2 \pm 3.5 \%$ ) i. e. 6 months after conversion from once daily soluble and protamine zinc insulin to twice daily soluble and isophane insulin (Fig. 1). This was not associated with a significant reduction in the daily insulin dose. Beef and pork insulin antibody binding also fell significantly $(p<0.05)$ between attendances 9 and 14, in patients transferred from soluble and isophane to Actrapid and Monotard insulin. This reduction was not found in patients who remained on soluble and isophane insulin.

One month after conversion from soluble and isophane to Actrapid and Monotard insulin, daily insulin dose had been reduced $(p<0.05)$ from $66 \pm$ 7 to $56 \pm 6$ units, i. e. by $15 \%$. No further significant reduction in insulin dose was observed thereafter despite the subsequent fall in insulin binding by antibodies. 


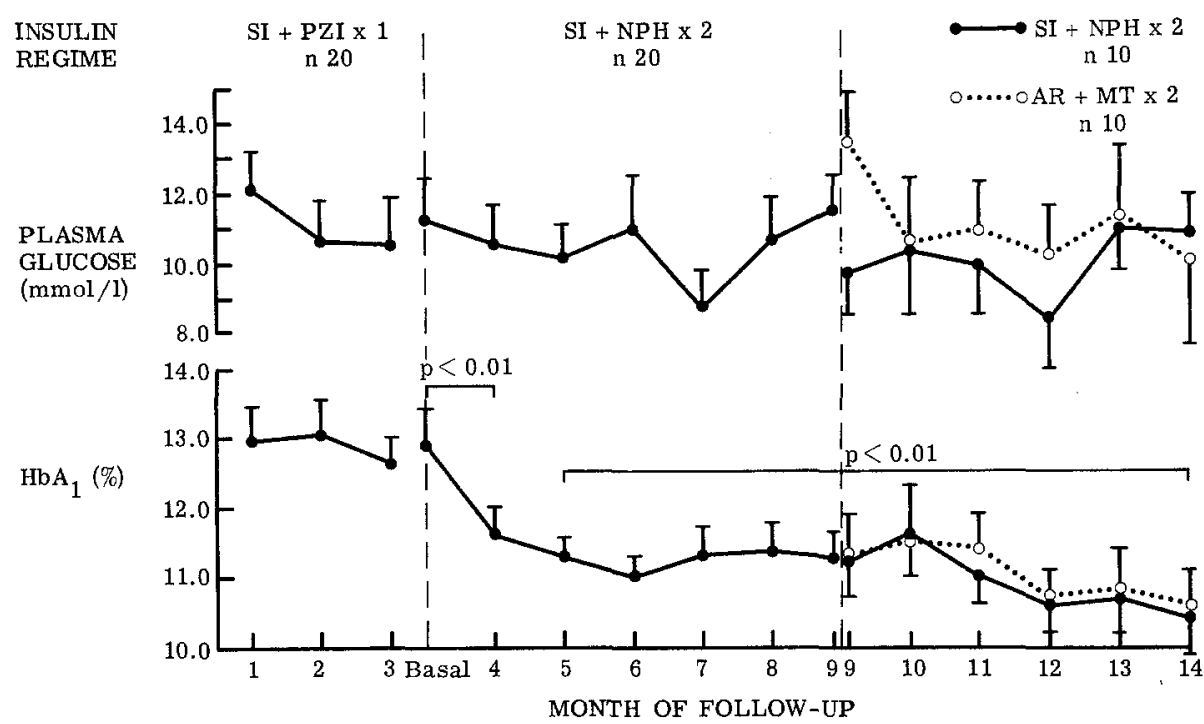

Fig. 2. Monthly, random, post-prandial glucose and $\mathrm{HbA}_{1}$ concentrations (mean $\pm S E M$ ) following conversion from a once daily conventional beef insulin regime to a twice daily conventional beef insulin regime, and then to a twice daily highly purified pork insulin regime. See Fig. 1 for abbreviations

\section{C-Peptide}

Of the 20 patients tested at clinic attendance 3 , only nine showed a measurable response with a median $\Delta$ $\mathrm{C}-\mathrm{P}$ of $0.05 \mathrm{nmol} / \mathrm{l}$. When the 20 patients were retested at clinic attendance 9 , the same nine C-peptide secretors were the only patients to exhibit a measurable response (median $\Delta \mathrm{C}-\mathrm{P} 0.04 \mathrm{nmol} / \mathrm{l}$ ), there being a highly significant correlation between $\Delta \mathrm{C}-\mathrm{P}$ at attendances 3 and $9(r=0.93, p<0.01)$. Basal $C$ peptide concentrations in non-secretors were all less than $0.04 \mathrm{nmol} / \mathrm{l}$.

\section{Diabetic Control}

There were no significant differences between consecutive $\mathrm{HbA}_{1}$ levels, random plasma glucose concentrations, degrees of glycosuria or frequency of symptomatic hypoglycaemia during the first two months of the study (three attendances) when the patients received soluble and protamine zinc insulin once daily, and these variables were, therefore, each averaged and expressed as a basal value.

One month after conversion to twice daily soluble and isophane insulin, $\mathrm{HbA}_{1}$ fell from a basal value of $12.9 \pm 0.5$ to $11.6 \pm 0.4 \%(p<0.01)$ (Fig. 2$)$. The mean degree of late evening glycosuria fell $(p<$ 0.01 ) from a basal value of $2.7 \pm 0.3$ to $1.7 \pm 0.3$ units one month later, an improvement which was sustained throughout the study. When degree of glycosuria for each time of the day was expressed as a mean value for months $3-13$ inclusive, only late evening glycosuria (1.6 \pm 0.04 units) showed a significant reduction from the basal value $(p<0.01)$, There were no significant differences between esti- mates of basal glycosuria before breakfast $(2.1 \pm 0.3$ units), before lunch ( $1.3 \pm 0.2$ units) and before tea (2.1 \pm 0.2 units) and those recorded for months 3-13 $(1.6 \pm 0.04,1.1 \pm 0.02$ and $1.7 \pm 0.02$ units $)$. Figure 2 shows the mean plasma glucose concentration recorded at each clinic attendance. With the above exceptions, no significant differences were observed when comparing consecutive monthly indices of diabetic control. However, the mean $\mathrm{HbA}_{1}$ concentration at attendance $14(10.5 \pm 0.3 \%)$ was lower $(p$ $<0.01)$ than that at attendance $5(11.3 \pm 0.3 \%)$ when all 20 patients were considered together.

There were no significant differences between patients treated with soluble and isophane insulin and those treated with Actrapid and Monotard insulin in respect of plasma glucose and $\mathrm{HbA}_{1}$ concentrations (Fig. 2), nor in respect of glycosuria nor symptomatic hypoglycaemia.

There was no significant difference between mean basal $\mathrm{HbA}_{1}$ values of C-peptide secretors (12.6 $\pm 0.7 \%)$ and non-secretors $(13.1 \pm 0.6 \%)$, nor between patients with low $(13.6 \pm 0.8 \%)$ and high $(12.1 \pm 0.4 \%)$ insulin antibody binding. For the latter comparison, the 20 patients were ranked according to their insulin antibody binding estimated at the third attendance and divided into two groups of ten, having the lowest and the highest binding respectively.

Each patient's basal $\mathrm{HbA}_{1}$ concentration was compared with the mean concentration recorded at attendances 5-14 inclusive, whereby individual changes in $\mathrm{HbA}_{1}$ in response to conversion from a once to twice daily insulin regimen were assessed. Eighteen patients $(85 \%)$ showed a reduction, while three patients $(15 \%)$ showed an increase in $\mathrm{HbA}_{1}$. 
When the mean change in $\mathrm{HbA}_{1}$ following conversion from a once to a twice-daily insulin regimen was compared between $\mathrm{C}$-peptide secretors $(-1.7 \pm$ $0.7 \%)$ and non-secretors $(-1.9 \pm 0.3 \%)$ and between patients with low $(-2.3 \pm 0.5 \%)$ and high $(-1.2 \pm 0.4 \%)$ insulin antibody binding, respectively, no significant difference was found. However, when C-peptide non-secretors were considered alone, patients with low insulin antibody binding showed a significantly greater $(p<0.01)$ change in $\mathrm{HbA}_{1}(-2.8 \pm 0.3 \%)$ than in patients with high insulin antibody binding $(-1.2 \pm 0.5 \%)$. Individual reductions in $\mathrm{HbA}_{1}$ following conversion from a once to a twice daily insulin regime showed a significant negative correlation with beef insulin antibody binding estimated at attendance $3(r=0.62, p<0.05)$, in $\mathrm{C}$-peptide non-secretors, but not in C-peptide secretors $(r=0.38)$.

Throughout the study each patient maintained a normal haemoglobin and reticulocyte count.

\section{Discussion}

Twice daily insulin regimes may help in the management of "unsatisfactorily" controlled [10], "severe" [11], or "labile" [12] diabetics, whose metabolic control has been assessed in terms of pre-meal plasma glucose and ketone concentrations, or degree of glycosuria or ketonuria. The present study shows that in our patients receiving once daily insulin the change to a twice daily regime was associated with a fall in $\mathrm{HbA}_{1}$ concentration. Such a change in insulin regime cannot be effected "blind" and, therefore, the possibility remains that part of the improvement in $\mathrm{HbA}_{1}$ concentration may be due to greater effort on behalf of patient and doctor to improve diabetic control. On the other hand, it seems likely that the reduction in late evening glycosuria is due to the evening dose of soluble insulin and may largely account for the concomitant fall in $\mathrm{HbA}_{1}$. Our findings contrast with a previous comparison [13] of $24 \mathrm{~h}$ metabolic profiles of inpatients receiving once daily Actrapid and Monotard insulin and twice daily Actrapid and Semitard (Novo) insulin. In the latter study, no significant difference in mean $24 \mathrm{~h}$ plasma glucose nor $24 \mathrm{~h}$ urinary glucose excretion was observed, possibly because Semitard's duration of action may be shorter than that of isophane. Alternatively, the indices of diabetic control used by Werther et al. [13] may have been insufficiently sensitive, by comparison with $\mathrm{HbA}_{1}$, to detect an improvement in control. Nevertheless, the once daily regime was accompanied by significantly greater hyperglycaemia in the late evening than the twice daily regime [13], in accordance with our own findings.
Of further interest is the considerable individual variation in $\mathrm{HbA}_{1}$ response to a change from a once to a twice daily insulin regime. It has been suggested $[14,15]$ that in patients who have no endogenous insulin secretion, high insulin antibody binding may improve diabetic control by prolonging the half-life of insulin [16, 17]. Thus, C-peptide non-secretors with low insulin antibody binding might be expected to gain particular advantage from an evening dose of insulin. In accordance with such a hypothesis, our findings suggest that in C-peptide non-secretors the improvement in $\mathrm{HbA}_{1}$ following conversion from a once to a twice daily insulin regime, shows an inverse correlation with initial insulin antibody binding. This observation also encourages us to believe that the reduction in $\mathrm{HbA}_{1}$ is not solely due to improved patient compliance. It is of interest that the continuing secretion of $\mathrm{C}$-peptide, which has been shown to reduce $\mathrm{HbA}_{1}$ concentrations in insulin treated diabetics [18], is not associated with a reduction in $\mathrm{HbA}_{1}$ response to the change in insulin regime.

A number of reports [19-22] claim an improvement in metabolic control following conversion from conventional beef to highly purified pork insulin. However, in these studies, the patients were selected on the basis of metabolic lability, high insulin requirement or insulin allergy and diabetic control was assessed by unsatisfactory means. Moreover, the studies were uncontrolled. We now show that highly purified pork insulin, when delivered as a twice-daily insulin regime, does not carry any advantage over conventional beef insulin. A small but significant reduction in $\mathrm{HbA}_{1}$ was observed between attendances 5 and 14 when all twenty patients were considered together. It seems likely that this improvement in diabetic control is due to the close supervision of the patients studied leading to greater compliance. Omission of a control group of patients would have led to the erroneous conclusion that the highly purified pork insulins were responsible for the improvement in $\mathrm{HbA}_{1}$ concentrations.

The method used to characterise insulin antibody binding restricts us from commenting on changes in insulin antibody binding capacity or affinity characteristics. Nevertheless, in accordance with previous studies $[5,23,24]$ we have shown that beef and pork insulin antibody binding is reduced after conversion from conventional beef to highly purified pork insulin. We have also shown considerable reduction in insulin antibody binding after conversion from protamine zinc to isophane insulin, suggesting that the high ratio of protamine to insulin in protamine zinc insulin may be increasing insulin's antigenicity [25]. It is of interest that this reduction in insulin antibody binding has little influence on daily insulin dose. The 
immediate fall in insulin dose after conversion to highly purified pork insulin may reflect lower binding affinity of insulin antibody for highly purified pork as compared with conventional beef insulin [21]. However, we cannot deny the possibility that the reduction in insulin dose merely reflects the advice given to each patient, according to the recommendations of the insulin manufacturers. Our patients did not encounter frequent, profound hypoglycaemia, as described by Asplin et al. [21], many of whose patients had required a large dose of once daily insulin and had been poorly controlled prior to conversion of insulin regime.

In conclusion, our findings suggest that a twice daily insulin regime provides better glycaemic control than a once daily regime, but that highly purified pork insulin offers no such advantage over conventional beef insulin, when administered twice daily. Cpeptide non-secretors with low insulin antibody binding show the greatest improvement of control on changing from once to twice daily insulin.

Acknowledgements. The authors gratefully acknowledge the technical assistance provided by Judith Matthews and Margaret Sinclair, and the financial support of Pfizer, Europe, which helped to establish the assay for $\mathrm{HbA}_{1}$. We are also indebted to Miss C. M. Hepburn for her invaluable secretarial assistance. ABK was supported by a grant from Nordisk Insulin Laboratorium.

\section{References}

1. Koenig RJ, Peterson CM, Kilo C, Cerami A, Williamson JR (1976) Hemoglobin $A_{1 \mathrm{c}}$ as an indicator of the degree of glucose intolerance in diabetes. Diabetes 25: 230-232

2. Gonen B, Rubenstein AH, Rochman H, Tanega SP, Horwitz DL (1977) Haemoglobin, A1: An indicator of the metabolic control of diabetic patients. Lancet 2: 734-737

3. Gabbay KH, Hasty K, Breslow JL, Ellison RC, Bunn HF, Gallop PM (1977) Glycosylated hemoglobins and long-term blood glucose control in diabetes mellitus. J Clin Endocrinol Metab 44: 859-864

4. Build and blood pressure study, Vol 1 (1959) Chicago, Society of Actuaries

5. Kurtz AB, Matthews JA, Mustaffa BE, Daggett DR, Nabarro JDN (1980) Reduction of antibodies to insulin, proinsulin and contaminating hormones after changing from conventional beef to purified pork insulin. Diabetologia 18: $142-150$

6. Heding LG (1978) Radioimmunological determination of human C-peptide in serum. Diabetologia 11: 541-548

7. Morley G, Dawson A, Marks J (1968) Manual and autoanalyser methods for measuring blood glucose using guaiacum and glucose oxidase. Proc Assoc Clin Biochem 5: 42-45

8. Kynoch PAM, Lehmann H (1977) Rapid estimation ( $2^{1 / 2}$ hours) of glycosylated haemoglobin for routine purposes. Lancet 2: 16-17
9. Svendsen PAa, Christiansen JS, Soegaard U, Welinder BS, Nerup J (1980) Rapid changes in chromatographically determined haemoglobin $A_{1 c}$ induced by short-term changes in glucose concentration. Diabetologia 19: 130-136

10. Clarke BF, Munro JF, Duncan LJP (1965) Time-action studies and clinical trial of Actrapid and Crystall II. Novo Insulins. Br Med J 2: 265-267

11. Oakley W, Hill D, Oakley N (1966) Combined use of regular and crystalline protamine (NPH) insulins in the treatment of severe diabetes. Diabetes 15: 219-222

12. Akerbloom HK, Heikkela H (1970) Diurnal blood and urine glucose and acetone bodies in labile juvenile diabetics on one and two injection insulin therapy. Diabetologia 6: 130-134

13. Werther GA, Jenkins PA, Turner RC, Baum JD (1980) 24 hour metabolic profiles in diabetic children on once or twice daily insulin injections. Br Med J 2: 414-418

14. Dixon K, Exon PD, Hughes HR (1972) Insulin antibodies in aetiology of labile diabetes. Lancet 1: 343-347

15. Dixon K, Exon PD, Malins JM (1975) Insulin antibodies and the control of diabetes. Q J Med 44: 543-553

16. Bolinger RE, Morris JH, McNight FG, Diederlich DA (1964) Disappearance of $\mathrm{I}^{131}$ labelled insulin from plasma as a guide to management of diabetes. $N$ Engl $J$ Med 270: 767-770

17. McAdams GB, Knox KR, Wilcox DS (1967) The initial rapidphase disappearance of intravenous radioinsulin in diabetes. $\mathrm{J}$ Nucl Med 8: 173-178

18. Gonen B, Goldman J, Baldwin D, Goldberg RB, Ryan WG, Blix PM, Schanzlin D, Fritz KJ, Rubenstein AH (1979) Metabolic control in diabetic patients. Effect of insulin-secretory reserve (measured by plasma C-peptide levels) and circulatory insulin antibodies. Diabetes 28: 749-753

19. Lithner F (1975) Treatment of diabetes mellitus with monocomponent insulin. Opusc Med 20: 249-294

20. Bruni B, Bruni Bocher K, Gamba S, Giolitti A, Rittatore R, Turco GL (1977) Long-term clinical trial with porcine monocomponent Lente insulin. Pan med 19: 247-253

21. Asplin CM, Hartog M, Goldie DJ (1978) Change of insulin dosage, circulating free and bound insulin and insulin antibodies on transferring diabetics from conventional to highly purified porcine insulin. Diabetologia 14: 99-105

22. Griffin NK, Smith MA, Baum JD (1979) Reduction of insulin dose on changing diabetic children from standard to monocomponent insulins. Arch Dis Child 54: 123-126

23. Bruni B, D'Alberto M, Osenda M, Ricci C, Turco GL (1973) Clinical trial with monocomponent Lente insulins. Diabetologia 9: 492-498

24. Csyzyk A, Laiuecki J, Rogala H, Miedzinska E, Popik-Hankiewicz A (1974) Serum levels of insulin-binding antibodies in diabetic patients treated with monocomponent insulin. Diabetologia 10: 233-236

25. Kahn CR, Rosenthal AS, Mann D, Blake T, Galloway J (1979) Immunologic reactions to insulin in man. Diabetes 28 : Abstract 211

Received: 5 September 1980

and in revised form: 13 April 1981

Dr. R. S. Gray

Diabetic and Dietetic Departmant,

Royal Infirmary

Edinburgh, EH3 9YW, Scotland 